\title{
Organizaciones del Estado que promueven la economía social en el gobierno de Chávez*
}

\author{
Argüello, Iris**
}

\section{Resumen}

Con el gobierno que se inicia en Venezuela en 1999, se crean instrumentos legales y surgen instituciones que le dan relevancia al sector de la economía social, conformado por cooperativas, ONG's, y microempresas. El objetivo del presente trabajo es explorar la política que formalmente promueven las organizaciones del Estado que impulsan la economía social en el gobierno de Chávez, específicamente las que estuvieron adscritas al Ministerio de Economía Social. La metodología consistió en el análisis documental y entrevistas semiestructuradas a los funcionarios de las instituciones. Los resultados revelan que; 1) En el marco de una constitución y leyes que promueven la economía social, se crean nuevas organizaciones para el desarrollo de programas en este sector, 2) Existe una concepción del desarrollo en etapa de construcción donde se privilegia lo sustentable y lo endógeno; y 3) Se promueven programas sociales compensatorios conjuntamente con actividades productivas que privilegian microempresas y especialmente formas colectivas de organización cooperativa. Se concluye que las organizaciones del Estado para promover la economía social contribuyen con el modelo de desarrollo endógeno, fundamentado en la búsqueda de la transformación socioproductiva y cultural del modo de producción capitalista dominante.

Palabras clave: Economía social, organizaciones estatales, gobierno de Chávez.

\section{State Organizations that Promote the Social Economy of the Chavez Government}

\section{Abstract}

With the government that initiated its term in Venezuela in 1999, legal instruments were created and institutions developed that give relevance to the social economy sector, specifically coop-

\section{Recibido: 04-12-15. Aceptado: 05-09-26}

Esta investigación es parte del trabajo de tesis de Maestría en la Universidad del Zulia (LUZ) en Venezuela) titulada "Gestión de las Organizaciones que Promueven la Economía Social en Venezuela (1999-2004); adscrita como proyecto de investigación, al Programa Política y Administración Subnacional, del Centro de Estudios de la Empresa de la Universidad del Zulia.

** Socióloga. Magíster en Gerencia Pública (LUZ). Estudiante del Doctorado en Ciencias Sociales, Mención: Gerencia (LUZ). Docente de la Universidad Bolivariana de Venezuela.

E-mail: irisemil@yahoo.com 
eratives, NGOs and micro-businesses. The objective of this paper is to explore policies that formally promoted the state organizations that promoted social economy in the Chavez government, specifically those that were registered in the Social Economy Ministry. The methodology of this study was comprised of documentary analysis and semi-structured interviews with the managers of these institutions. The results reveal that; 1) Within the framework of the constitution and the laws that promote social economy, new organizations were created to develop programs in this sector, 2) There is a conception of development in the construction stage that favours what is sustainable and endogenous; and 3) Compensatory social programs are promoted with productive activities that favour microbusinesses and collective cooperative enterprises. The conclusion is that in order for state organizations to promote a social economy that contributes to the endogenous development model, they must base it on the search for socio-productive and cultural transformation of the dominant capitalist production model.

Key words: Social economy, state organizations, the Chavez government.

\section{Introducción}

En el gobierno de Chávez se intenta llevar a cabo un modelo de desarrollo alternativo, plasmado en su propuesta electoral, en la nueva constitución y en los lineamientos de acción del Plan $\mathrm{Na}$ cional, documentos en los cuales se pone un especial énfasis en la economía social impulsada y fomentada en la práctica desde distintas instituciones del Estado Venezolano, producto de lo cual tienen lugar una serie de cambios en materia jurídica y organizativa.

Con la aprobación de la Constitución de la República Bolivariana de Venezuela (CRBV) a través de refrendo en 1999, adquieren rango constitucional las organizaciones de la economía social; además que se crean mediante Ley habilitante, la Ley de Estimulo Promoción y Desarrollo del Sistema Microfinanciero y la Ley Especial de Asociaciones Cooperativas (LEAC), las cuales rigen dos tipos de organizaciones que pertenecen al sector de la economía so- cial: las cooperativas y las microempresas.

Asimismo, el gobierno presenta un mayor interés en la integración de lo económico y lo social, apoyando estrategias productivas solidarias y creando nuevas instituciones para la promoción de la economía social, entre las que se encuentran las siguientes: Instituto Autónomo Fondo Único Social (IAFUS), Banco del Pueblo Soberano (BPS), Fondo de Desarrollo Microfinanciero (FONDEMI), Banco de Desarrollo de la Mujer (BANMUJER) y el Banco de Desarrollo Económico y Social (BANDES).

Con la Ley de Microfinanzas, se crea el Sistema Microfinanciero, del cual forman parte el BPS, BANMUJER y FONDEMI; este último constituido, según la mencionada ley, en el órgano rector. El Banco del Pueblo representa la primera experiencia y organización del sector de las microfinanzas creada por el mencionado gobierno; de igual forma BANMUJER se constituye en la primera banca social de género en Venezuela. 
Se crea el IAFUS como ente concentrador de recursos; a la vez que el BANDES se constituye en una banca que fomenta el sector de las microfinanzas y grandes proyectos industriales, orientado formalmente hacia el desarrollo sustentable del país.

Adicionalmente, surge una instancia de coordinación, el Ministro de Estado para el Desarrollo de la Economía Social (MEDES), sustituido por el Ministerio de Economía Popular (MINEP), actual ente rector de la economía social en Venezuela.

El objetivo de está investigación es explorar la política de economía social, promovida por las organizaciones del Estado en el gobierno de Chávez en el período 1999-2004, específicamente las adscritas al Ministro de Estado para el Desarrollo de la Economía Social (MEDES).

Los cambios que están sucediendo en el aparato del Estado, entre los cuales se encuentra la política de economía social, han sido poco estudiados, por lo que no existen trabajos que recojan las expe- riencias de las nuevas instituciones creadas; haciendo necesario la producción de conocimiento, explorando un área poco o casi nada estudiada, que sirva de base para futuras investigaciones y propuestas de cambios.

Partimos del supuesto de que la política de economía social, ha presentado avances para impulsar formas de organización cooperativa más allá del apoyo dado al sector microempresarial basado en un microempresario individualista. La metodología empleada, se baso en el análisis documental y en entrevistas abiertas aplicadas a los funcionarios de las instituciones objeto de estudio, en una investigación exploratoria con intentos de explicación.

\section{Hacia una política de economía social sustentada en el desarrollo endógeno}

La economía social como política de Estado no es una novedad, ésta ha sido promovida por diferentes gobiernos ${ }^{1}$

Las primeras leyes en materia de economía social, datan de la época de Gómez, en 1910 y 1917 para regir el sector cooperativo; el cual goza de rango constitucional desde 1961 siendo el más institucionalizado, con la creación de la Superintendencia Nacional de Cooperativas (SUNACOOP) desde 1966 y su primera Central de Cooperativas Regional desde 1967. En cuanto al del sector microempresarial, se crea en 1959, la Comisión Artesanal de Crédito al Artesanado y Pequeña Industria, reestructurada en 1961 como Comisión Nacional de Financiamiento a la Pequeña y Mediana Industria y finalmente sustituida en 1974 por la Corporación de Desarrollo de la Pequeña y Mediana Industria (CORPOINDUSTRIA), la cual con la Fundación para el Desarrollo de la Comunidad (FUNDACOMUN) desarrolla programas de microcréditos dirigidos a organizaciones económicas de base, para ser clausurados en 1988 (Barrantes en López, 2003: 36, 37). En 1987 se crea el Fondo de Cooperación y Financiamiento de Empresas Asociativas (FONCOFIN), para promover y fomentar el desarrollo de pequeñas unidades de promoción, dicho Fondo es eliminado en 1999. Durante el segundo gobierno de Carlos Andrés Pérez (1989-1993) se llevo a cabo con el Plan de Enfrentamiento a la Pobreza, el "Programa de Apoyo a la Economía Popular" y posteriormente en el segundo período de Rafael Caldera se creo el Programa de Economía Solidaria bajo lineamientos de la Agenda Venezuela, ambos 
mucho antes del actual. Lo novedoso o alternativo del proyecto de gobierno, se encuentra en la adopción de una concepción diferente del desarrollo, para la construcción y definición de un modelo basado fundamentalmente en la promoción de la economía social.

El modelo de desarrollo es calificado en la propuesta electoral de Chávez, como humanista, autogestionario y competitivo, prevé además, un sistema económico autogestionario, para el estimulo de la democratización económica y de formas organizativas alternas, como cooperativas y otros tipo de asociación, planteándose cinco equilibrios: político, social, económico, territorial y mundial. Cabe destacar la importancia dada a las estrategias productivas solidarias en dicha propuesta, para trascender el hecho netamente económico, permitiendo romper con las desigualdades, lo que significa una política social integra e integradora para permitir la ampliación de las capacidades productivas y de producción de la sociedad (MVR, 1998: 15-30).

El Estado Venezolano en la década del 2000, toma distancia del modelo de desarrollo neoliberal y se propone formalmente una transformación profunda de la estructura del modo de producción capitalista del sistema mundial hegemónico y de dominación. En principio, la noción del desarrollo utilizada por el gobierno apun- to hacia lo local y sustentable; a partir del año 2003 comienza a discutirse sobre el desarrollo endógeno, teniendo como punto de partida la tesis de Oswaldo Sunkel (1995).

El modelo de desarrollo caracterizado para la sustentabilidad, se expresa tanto en la propuesta electoral como en el plan de la nación (2001-2007), en el equilibrio territorial, centrado en la desconcentración para el desarrollo sustentable; teniendo como fin el incremento de la población y las actividades económicas en áreas de desconcentración, llamadas ejes de desarrollo, regiones y zonas especiales de desarrollo sustentable, para proporcionar un mejor nivel de vida, mediante las condiciones necesarias para ello y evitando el desplazamiento hacia grandes centros urbanos (MPD, 2001: 133).

Entre las estrategias del equilibrio territorial, se destaca la creación de zonas especiales de desarrollo sustentable (ZEDES) y la creación de microempresas, cooperativas y pequeñas empresas, con el fin de fortalecer las asociaciones solidarias básicas de la comunidad para la autogestión en distintas áreas, organizando a la sociedad civil en el medio rural a través de la diversificación de sus actividades productivas e impulsando la economía integral asociativa (MPD, 2001: 140-143). Por tanto, la política que impulsa la economía social es sustento indis-

programas fueron adscritos a FONCOFIN, prestando servicios de asistencia técnica, financiera y de comercialización a pequeños microempresarios. También desde la sociedad se crearon algunas ONGs, entre las cuales se encuentran: La Fundación Mendoza, el Centro al Servicio de la Acción Popular (CESAP) y el Equipo de Formación y Publicación (EFYP). 
pensable para llevar a cabo la construcción y consolidación del nuevo modelo de desarrollo.

Pacheco (2004: 206), con fundamento en lo territorial, plantea el desarrollo como sustentable y básicamente endógeno y define este último como "los procesos que incrementan la producción social integral corrigiendo los desequilibrios (polarización y exclusión) en una relación ambientalmente sustentable". Pacheco (2004: 52-55) se refiere al desarroIlo considerando varios elementos; en primer término, señala el desarrollo autocentrado, como un modo de cambiar la estructura jerárquica de polarización bajo la aplicación de modelos de crecimiento autocentrado; en segundo término, refiere la utilización de recursos y soluciones competitivas por las comunidades, bajo relación entre regiones tanto nacionales como con el entorno continental cercano, permitiendo crear economías de escala que puedan generar externalidades a las empresas para que se sedentaricen en sus localidades, colocando acento en la acumulación de capital en localidades territoriales concretas; finalmente destaca el desarrollo como soberano, reinvirtiendo los excedentes generados en el proceso de reproducción social, dentro del país, para provocar la acumulación de capitales y crear riqueza interna en lugar de ser soportes de los países desarrollados.

En un intento de aproximación a la noción de desarrollo endógeno, autores como Carlos Lanz (2004르) lo define como desarrollo desde adentro, por lo que es necesario diferenciarlo del desarrollo hacia dentro, ya que en el Estado benefactor y con el modelo de sustitución de im- portaciones, la lógica de funcionamiento se oriento hacia este último.

Según Sunkel (1995: 63-65) por un lado, el desarrollo hacia dentro, coloca énfasis en la demanda, expansión del mercado interno y el reemplazo de los bienes importados por la producción local; dicha estrategia está basada en ampliar el consumo interno y en reproducir localmente los patrones de consumo, producción industrial y tecnología de los centros, a través de la sustitución de importaciones, configurada con una distribución desigual de ingreso interno y sin colocar acento en la acumulación, el progreso técnico y la productividad; por otro lado, el desarrollo desde dentro, más allá de satisfacer la demanda final del consumo de los sectores de ingresos medios y altos, debe orientarse hacia determinados mercados internos y externos permitiendo la inserción en la economía mundial, aprovechando los recursos naturales y adoptando estilos de vida acordes al medio natural y humano, para el logro de un verdadero desarrollo nacional y regional.

A su vez Pacheco (2004: 55, 56), afirma que el desarrollo hacia adentro, "propicia la sustitución de importaciones dejando incólume los patrones de consumo y las relaciones sociales"; $y$ en el modelo de desarrollo endógeno desde adentro, se "producen 'enclaves locales que separan a las regiones internas y establecen vínculos lineales con los países centrales dentro de lo que denominan 'globalización"; por lo que el desarrollo endógeno tiene elementos de ambas posiciones, sustituyendo importaciones, modificando los parámetros de consumo, exportando, privilegiando el contexto latino- 
americano y los aliados estratégicos, y se apoya en las conexiones y relaciones entre las distintas regiones y localidades internas.

Otra posición del desarrollo endógeno es la que defiende Carlos Lanz (2004a), proponiendo superar la tesis de Oswaldo Sunkel ${ }^{2}$, reivindicando "la subjetividad del actor político, la internalidad, porque el desarrollo endógeno nace desde adentro, por dentro... pero más allá de esa definición también hay que recuperar la dimensión cultural de lo endógeno, lo propio, nuestra herencia, nuestras raíces". Este nuevo enfoque del desarrollo, bajo una visión integral de lo endógeno, reconoce no solo los recursos naturales, sino el hombre, el sujeto, la cultura, el desarrollo humano integral, no se trata solo de crecimiento; en definitiva tiene que ver con otros valores, otra concepción de la economía, de lo social, de lo político y cambios en la relaciones de producción y de propiedad ${ }^{3}$; bajo un modelo mixto, en transición hacia otro tipo de sociedad, planteándose una alianza estratégica entre la propiedad estatal y formas asociativas de producción, con formas de propiedad colectiva, superando la propiedad privada de los medios de producción.
De igual forma, el autor maneja la sustentabilidad como elemento importante del enfoque de desarrollo endógeno, con posibilidades de mantenerse los proyectos en el tiempo, preservando el ambiente, la biodiversidad; sustentabilidad no solo en términos ambientales, sino económica, cultural, política. Un último señalamiento con respecto al desarrollo endógeno, se enfoca hacia su expresión territorial, ya que el desarrollo se ha concentrado en ciertas poblaciones del territorio, focalizado en una serie de enclaves económicos, dejando sin desarrollo otros lugares, que incluso no tienen posibilidad de acceder a servicios; en este sentido, son necesarios nuevos ejes de desarroIlo, aún cuando todo no puede ser sólo un problema territorial.

Es importante aclarar el contexto transitorio por el cual pasa el modelo de desarrollo endógeno y las nuevas relaciones de producción en construcción, hacia cambios y transformaciones en un proceso inacabado. Sin embargo, considerando la formas de propiedad que distingue Lanz (2004a), entre las cuales se destaca la economía solidaria, social o popular, o formas colectivas de propiedad; formalmente es mucho lo que se ha avanzado

2 Refiere la tesis neoestructuralista de dicho autor, como concepción que no comparte totalmente por sus raíces estructuralistas; incluso puede tener rasgos de industrialismo. En el enfoque de este autor no aparece la economía social, solidaria, ni popular, lo sustentable, la sustentabilidad, el papel de la subjetividad, ya que los neoestructuralistas no reconocen el papel central del sujeto (Lanz, 2004a).

3 Según Lanz (2004a) hay cuatro formas de propiedad, la estatal, sobre industrias básicas recursos naturales, y sobre bienes y servicios; la mixta, que es una mezcla de propiedad privada y estatal; la privada, dividida en propiedad monopolista o capital no monopolista con la pequeña y mediana producción muchas veces no monopolizado; y la economía solidaria, social o popular. 
hacia una política que apoye, impulse o fomente la conformación de dichas organizaciones o formas de propiedad, que puedan generar un cambio en las relaciones de producción.

En este período de gobierno se producen importantes reformas en materia constitucional y legal, las cuales sustentan el nuevo modelo de desarrollo y la política de economía social que éste conlleva. Entre las principales transformaciones se encuentra la aprobación de la Constitución de la República Bolivariana de Venezuela (CRBV) a través de un referéndum consultivo a finales de 1999, pocos meses después que Hugo Chávez Frías asume la presidencia.

El término de economía social es incluido en el artículo 184 de la CRBV, según el cual, se promueve la participación en los procesos económicos, mediante el estimulo de expresiones de la economía social, tales como cooperativas, cajas de ahorro, mutuales y otras formas asociativas; además que se plantea la promoción de las organizaciones de la economía social por medio de las políticas de Estado (ANC, 1999). En el artículo 118 se señala la existencia de un sector popular de la economía, garantizando el derecho a asociarse para desarrollar actividades económicas, a la vez que se identifican diferentes formas de organización de dicho sector (cooperativas, cajas de ahorro, mutuales y otras formas asociativas), reconociendo las especificidades de las organizaciones que lo componen, planteando su promoción y protección por parte del Estado; esto último ratificado en el artículo № 300 , teniendo como fin fortalecer el desarrollo económico del país, sustentándolo en la iniciativa popular, asegurando la capacitación, asistencia técnica y el financiamiento oportuno. Finalmente, el artículo 70 expresa como medios de participación, las organizaciones que pertenecen al sector de la economía social, haciendo mención a valores como cooperación y solidaridad, dejando ver la concepción de lo económico y social de manera más integral (ANC, 1999).

Luego de los cambios constitucionales, el enfoque del proyecto político del gobierno, se orienta hacia la Integración de lo económico y lo social, expuesto en el Plan Nacional de Desarrollo Económico y Social 2001-2007 (PNDES) y en un documento presentado por el gobierno en la Cumbre Mundial de Desarrollo Social en Ginebra, Suiza, en el cual se plasman los lineamientos de la política social del país. En este sentido, el primer documento señala que "el logro del equilibrio económico y la reactivación del aparato productivo son requisitos para una mejor distribución del ingreso, y que un mayor ingreso familiar y comunitario contribuye a alcanzar un equilibrio social. Pero el logro del equilibrio económico no se alcanza por sí sólo, ello demanda justicia social. Lo económico afecta lo social, y a la inversa ..." (MPD, 2001: 8). El segundo documento se propone que lo social y lo económico gocen de un mismo status, a fin de planificar la política de crecimiento económico con equidad social (MSDS, 2000: 23).

Formalmente la economía social es entendida por el gobierno, como una vía alternativa y complementaria a la economía privada y pública, sirviendo para distinguir un sector de producción de bienes y servicios que conjuga intereses comunes, tanto económicos como sociales, 
que debe estar apoyado en el dinamismo de las comunidades locales, con la participación de lo ciudadanos y de los trabajadores de las denominadas empresas alternativas, entre ellas las empresas asociativas y las microempresas autogestionables (MPD, 2001: 27).

Lo expuesto, deja ver que la política de economía social planteada en el proyecto de gobierno, en el plan de la nación, y en los lineamientos de la política social, tiene una visión integradora de lo económico y lo social; como estrategia se impulsan formas de organización alternas como cooperativas, microempresas y otras formas asociativas, orientadas hacia una mayor justicia social y equidad, fomentando la autogestión y la solidaridad.

Los instrumentos legales que sustentan la economía social en Venezuela, lo constituyen la Ley de Microfinanzas (Presidencia de la República Bolivariana de Venezuela, 2001a) y la Ley Especial de Asociaciones Cooperativas (LEAC) (Presidencia de la República Bolivariana de Venezuela, 2001b). La primera tiene como objeto la creación, estímulo y promoción del sistema microfinanciero, para atender la economía popular, a fin de incorporarla a la dinámica del desarrollo económico y social. En cuanto a la segunda, tiene como objeto ser el marco normativo para la organización y funcionamiento de las cooperativas. En la mencionada Ley se definen a las cooperativas como asociaciones abiertas y flexibles, de hecho y de derecho cooperativo, de la economía social y participativa, autónomas, de personas que se unen de manera voluntaria, para hacer frente a sus necesidades y aspiraciones económicas, sociales y culturales comunes, para ge- nerar bienestar integral, colectivo y personal por medio de procesos y empresas de propiedad colectiva, gestionadas y controladas democráticamente.

El avance y desarrollo de la política alternativa de economía social del gobierno venezolano, se materializa formalmente en una primera etapa en la que se destacan entre los cambios más relevantes, no solo una nueva concepción del desarrollo aún en etapa de construcción, definición y consolidación, sino, el afianzamiento del marco jurídico, constitucional y legal a través de nuevas leyes (Ley de Cooperativas y la Ley de Microfinanzas) para regir lo concerniente a dos tipos de organizaciones de la economía social, (microempresas y cooperativas); y el marco institucional con la creación de diversas organizaciones para poner en práctica los lineamientos de la política.

Por tanto, formalmente, el marco jurídico de la economía social es complementado con instrumentos legales y programas para las nuevas instituciones.

\section{Las nuevas instituciones para promover la economía social}

La creación de diversas organizaciones para impulsar la economía social en Venezuela, ha sido una de las principales líneas de acción del gobierno, planteadas en el PNDES. Se han creado nuevas instituciones y se han transformado otras; entre ellas EI IAFUS; las pertenecientes al sistema microfinanciero: el BPS, FONDEMI y BANMUJER; $y$ el BANDES.

De igual forma, en el PNDES se traza como estrategia, la constitución de una instancia de coordinación sectorial 
para garantizar el cumplimiento de las acciones a llevar a cabo en la política de economía social, por lo que se nombra el MEDES, cumpliendo con el esfuerzo de crear un órgano rector en el área señalada, al cual se adscriben todas las instituciones mencionadas, creadas mucho antes que el MEDES, por lo cual estuvieron en principio adscritas al Ministerio de Finanzas (BPS, FONDEMI y BANMUJER), al Ministerio de Salud y Desarrollo Social (IAFUS) y al Ministerio de Planificación y Desarrollo (BANDES). EI MEDES desaparece para ser sustituido por el MINEP, actual ente rector de la economía social.

\subsection{MEDES. Instancia de coordinación}

El MEDES se crea, en el año 2002, para asesorar al Presidente de la República en materia de protección y fomento de la economía social; teniendo a su cargo, formular, coordinar, dar seguimiento y evaluar las políticas que promuevan la economía social participativa y los programas para promover empresas y organizaciones de carácter asociativo y comunitario, constituidas como fuentes generadoras de bienestar personal y colectivo (Presidencia de la República Bolivariana de Venezuela, 2002).

La misión que se definió para el MEDES fue establecer las políticas rectoras para guiar la elaboración de planes, programas y proyectos para promover, desarrollar y consolidar la economía social participativa y sus entes adscritos; así como coadyuvar a los cambios actitudinales de la población venezolana para la transformación del modelo de distribución del ingreso y democratización del capital. En su visión se planteó ser el ministerio promotor de la economía social y participativa, para fortalecer el tejido social-productivo y brindar soporte al desarrollo de la justicia social y el bienestar económico, sirviendo de plataforma para el cambio estructural de la economía venezolana (Banco de Desarrollo Económico y Social, s/fa).

En el año 2002, se adscriben al MEDES: el IAFUS, el BPS, BANMUJER, FONDEMI y la Fundación Pueblo Soberano ${ }^{4}$. Posteriormente, en el año 2003, es adscrito el BANDES (Presidencia de la República Bolivariana de Venezuela, 2002; Presidencia de la República Bolivariana de Venezuela, 2003).

\subsection{EL IAFUS. Ente concentrador de recursos y ejecutor de programas compensatorios}

El IAFUS se crea en 1999, en principio como Servicio Autónomo Fondo Único Social (SAFUS), sin personalidad jurídica y con un apartado presupuestario dependiente del Ministerio de Salud y Desarrollo Social (Presidencia de la República Bolivariana de Venezuela, 1999). Posteriormente, en el año 2001, se congramas para promover la economía social, razón por la cual no es incluida en esta investigación. 
vierte en IAFUS, con personalidad jurídica y patrimonio propia e independiente de la República, cambiando su adscripción a la Secretaria de la República (Presidencia de la República Bolivariana de Venezuela, 2001c).

El objeto formal del IAFUS, es la concentración y coordinación eficiente de los procesos de captación, administración e inversión de recursos a fin de optimizar el desarrollo y ejecución de las políticas, planes y programas destinados a favorecer y fortalecer oportuna y eficazmente el desarrollo social, la salud integral y la educación; asimismo debe impulsar la economía popular, promover la creación y el desarrollo de microempresas y cooperativas como formas de participación popular, en la actividad económica y en la capacitación laboral de jóvenes y adultos (Presidencia de la República Bolivariana de Venezuela, 2001c). Se trata en definitiva de una institución que tiene entre sus responsabilidades la promoción de actividades productivas en la economía social; además del desarrollo social, la salud y la educación.

En la práctica, el IAFUS se ha dedicado fundamentalmente a ejecutar programas tradicionales de tipo social compensatorio. El propósito de este tipo de programas, es según Naciones Unidas (1997: 35, 36) "contribuir a satisfacer las necesidades básicas de personas o familiares en situación de pobreza y vulnerabilidad extrema, es decir, lo más pobre entre los pobres, los más desamparados. Ellos son los sectores indigentes que no alcanzan un mínimo de ingreso para sobrevivir y menos para capacitarse, sectores más vulnerables de la tercera edad, jubilados y pensionados; niños y mujeres jefas de hogar; trabajadores y sus familias en situaciones de crisis por cesantía temporal, recesión económica o cierre de actividades productivas".

EI IAFUS por un lado, ha ejecutado programas de tipo compensatorio, focalizando en una población vulnerable de niños, adolescentes y ancianos; y por otro, ha dado continuidad a programas de desarrollo social y de tipo educativo, algunos de ellos creados en la década de los noventa.

Entre estos programas se encuentran los siguientes:

Programa de dotación de uniformes escolares (DUE): surge con el Plan de Enfrentamiento a la Pobreza, en 1989, con el gobierno de Carlos Andrés Pérez. Actualmente, esta dirigido a escolares procedentes de familias de escasos recursos económicos, al mismo tiempo que crea fuentes de empleo a través de microempresas dedicadas a la confección, impulsando el desarrollo económico textil y del calzado nacional; se realiza en convenios con las alcaldías, gobernaciones y mediante procesos de licitación estatal (FUS, s/fa).

\section{Programa de alimentación esco-} lar (PAE): este programa se originó en 1996 a nivel nacional con la Agenda Venezuela, bajo el mandato de Rafael Caldera. Dirigido a niños y adolescentes escolarizados en los tres niveles de educación básica, ofreciendo el servicio de cocina escolar, para garantizar la su permanencia y prosecución en el sistema educativo, es un programa de carácter social pedagógico y nutricional; puede ejecutarse a través de asociaciones civiles de las escuelas, microempresas, centros de distribución y empresas privadas (FUS, $s / f b)$. 


\section{Programa de desarrollo comuni-} tario (PDC): tiene como finalidad de apoyar la organización, crecimiento e integración social, para fortalecer las redes locales de organización mediante procesos de participación; se desarrolla a través de las gobernaciones y las alcaldías, atendiendo aproximadamente más de 13.000 familias ubicadas en 99 núcleos de desarrollo (IAFUS, s/f).

Programa de atención integral al indigente (PAll): ofrece servicios a los indigentes de alimentación y cuido a través de educadores de calle, en convenio con la Federación Centro Cristiano para las Naciones, desde el año 2004 (Martínez, 2004).

EI IAFUS funciona, según (Martínez, 2004), como receptor de los recursos financieros para todos los programas que maneja el gobierno. Destacamos que formalmente el IAFUS, a la vez que ejecuta programas para el desarrollo social, de tipo educativo y en el área de la salud; tiene en sus objetivos, el impulso del sector de la economía popular; por lo que en el año 2004, para el área de microfinanzas, se diseñaron 2 programas que aún no han sido ejecutados: un programa de banca comunitaria, que son los microbancos para la comunidad; y el programa de microfinanzas y empleo local, que es para la entrega de créditos a personas naturales o jurídicas con iniciativas de proyectos productivos.

Podemos concluir que el IAFUS, es un ente concentrador de recursos, que ha desarrollado programas de tipo asistencialista y tiene previsto ejecutar programas hacia el área de las microfinanzas, tal como lo establecen sus estatutos de creación; sin embargo, aún cuando direc- tamente no ha llevado a la práctica estos programas, funge como ente que proporciona los recursos necesarios, a otras instancias del gobierno que desarrollan programas directos para promover la economía social.

\subsection{Organizaciones del sistema microfinanciero}

El sistema microfinanciero se encuentra conformado por un conjunto de entes $u$ organizaciones tanto públicas como privadas, que mediante el otorgamiento de servicios financieros y no financieros fomentan, promocionan, intermedian y financian a personas naturales (autoempleadas, desempleadas y microempresarios) y jurídicas, organizadas en unidades asociativas o microempresas, en áreas rurales y urbanas. Según la Ley de Microfinanzas, los entes de ejecución, son los facultados para llevar a cabo todas las actividades relacionadas con las microfinanzas, al realizar acciones para el adiestramiento, capacitación y asistencia tecnológica en lo referente a la constitución, organización, gestión de la actividad microfinanciera, producción, comercialización de los bienes y servicios y cualesquiera otras necesarias, a fin de incrementar la productividad y competitividad en el mercado. Pueden ser entes de ejecución las Asociaciones Civiles, Fundaciones, Fondos, Cooperativas de Ahorro y Crédito, otras organizaciones públicas o privadas y las instituciones financieras regidas por la Ley General de Bancos y otras Instituciones Financieras que manifiesten su voluntad de prestar los servicios expresos en la Ley de Microfinanzas (Presidencia de la República Bolivariana de Venezuela, 2001a:8, 11). El BPS, 
FONDEMI y BANMUJER se constituyen en tres instituciones creadas por parte de gobierno nacional para el fomento de la economía social en el área de las microfinanzas.

Cabe destacar, que ya en la década de los 90 se ejecutaban programas dirigidos al sector microempresarial, insertos dentro de las llamadas políticas productivistas "tendientes a incrementar la capacidad de generación de ingresos de los grupos pobres, lo que tiene la ventaja de crear condiciones de autosustentación y permanencia en el tiempo. Se trata de acciones de capacitación y reconversión de trabajadores, o dirigidas a mejorar la productividad de los microempresarios o pequeños empresarios urbanos y de los pequeños propietarios agrícolas.

Las políticas de apoyo deben consistir en programas de asistencia técnica, transferencia de tecnologías, acceso al crédito y sistemas de garantía, así como asistencia en la comercialización y exportación de la producción" (Naciones unidas, 1997: 36).

Entre los lineamientos de estas políticas de aumento de la productividad estuvieron la capacitación para el trabajo, asis- tencia técnica, legal, de comercialización y de financiamiento a microempresas, como estrategia laboral, bajo el discurso de superación de la pobreza, como una salida a la crisis económica y social. Asimismo, los programas desarrollados estaban dirigidos a microempresarios tanto individuales como solidarios ${ }^{5}$, criterios que como veremos a continuación, coinciden con la política del sector microfinanciero impulsada por el actual gobierno.

Si bien hacemos estas reflexiones para señalar la continuidad de algunos criterios, es conveniente destacar que la política alternativa se diferencia de la concepción del modelo neoliberal en el que se promovió la economía abierta de mercado y la competitividad, con el impulso de estrategias para enfrentar el desempleo y teniendo entre sus fines compensar o paliar medidas del ajuste estructural y la desestablización económica, de corte transitorio una vez superados los efectos de dicho ajuste; promoviendo un microempresario individual o posteriormente solidario; pero que en todo caso no tenían un marco jurídico que los regulase; se trató de estrategias dirigidas a lo que se consideró el sector informal de la economía ${ }^{6}$.

5 Según Barrantes, (citado por López, 2003: 65), refiriéndose al programa de Economía Popular (PAEP) ejecutado bajo el modelo neoliberal, aplicado por Carlos Andrés Pérez “... contrariamente a la concepción asociativista inspirada en la Economía Social, del gobierno de Jaime Lusinchi, la concepción de una Economía popular estaba sustentada sobre la base de un microempresario individual altamente productivo y hasta tecnologizado, con capacidad exportadora". El programa de economía solidaria se insertó según Barrantes (1997: 43), en una política extraída de la ética social cristiana en la que se ve en dicho sector los gérmenes de una sociedad comunitaria o solidaria que tiene como meta (formalmente y según el discurso) la lucha contra la pobreza y las activación de fuentes de empleo.

6 Según González (1996: 39, 39), el Programa de Apoyo a la Economía Popular (PAEP), fue uno de los programas ejecutados dirigidos a la economía informal y se ubicó en el área de empleo y seguridad social, para atender a la población de trabajadores. 
Como lo plantean López y Ochoa (2002: 26) en el escenario que impone la globalización, el aparato público apuntó hacia formas de gestión flexibles y rol destacado de pequeñas unidades organizacionales en los procesos de producción, ya que se adecuan con mayor facilidad a las necesidades de la lógica de acumulación del estado capitalista; por lo que en las políticas públicas eso se tradujo en mayor incentivo de las microempresas como política social altamente funcional a los requerimientos de la reestructuración neoliberal de la economía, lo que las hizo operar como colchón de ajuste y orientadas a reducir los derechos adquiridos en el estado de bienestar.

La política del actual gobierno ha dado un fuerte apoyo al sector cooperativo con un papel fundamental del mismo, teniendo previsto que los microempresarios puedan organizarse en cooperativas, que según Esteller (1995:117) son las forma más democrática de organización.

\subsubsection{BPS. La primera banca so-} cial

Se origina mediante la transformación de la Compañía de Arrendamiento Financiero, C.A. (FIVCA), en BPS, según la resolución № 002-1099 emitida por la Junta de Emergencia Financiera el 13 de Octubre de 1999 (Banco del Pueblo Soberano, s/f). Es la primera institución de las microfinanzas creada por el gobierno nacional, representando una experiencia novedosa y teniendo como objetivo principal, atender a las clases más necesitadas, generar empleo, potenciar la econo- mía popular y participativa, permitiendo el acceso a la banca a un gran sector desatendido tradicionalmente; brindando servicios a personas naturales, pequeñas empresas y microempresas, comunidades asociativas; prestándole asesoría financiera y la promoción o apoyo a cualquier actividad de intermediación financiera que tenga como finalidad el logro de su objeto (Banco del Pueblo Soberano, 2003: 1; Banco del Pueblo Soberano, 1999: 9). Los programas en ejecución, hasta el año 2004, fueron los siguientes (Banco del Pueblo Soberano, s/f):

Créditos menores: otorgados a personas de bajos recursos, pudiendo ser solicitado individualmente o a través de grupos solidarios ( 2 a 3 personas), con una tasa de interés al $1 \%$ anual, sin comisión por gastos administrativos. Los montos a otorgar van desde Bs. ${ }^{7} 310.400$ hasta Bs. 1.185.600, con un plazo de financiamiento hasta de 1 año.

\section{Créditos individuales y solida-} rios: otorgados individualmente o a través de grupos solidarios ( 2 a 5 personas), para negocios con más de tres meses de funcionamiento, con una tasa de interés al $12 \%$ anual, al momento de liquidación del crédito el banco descuenta el $5 \%$ del monto otorgado por gastos administrativos (tasa flat) y $4 \%$ para los casos de recrédito. Los montos a otorgar van desde Bs. 931.200 hasta Bs. 13.580 .000 , con un plazo de financiamiento hasta de 1 año; para los créditos individuales es necesario tener como garantía a un fiador. 


\section{Créditos para nuevos emprende-}

dores: para aquellas personas, que por su arte, profesión, oficio u objeto social, inician una empresa por sí mismos y con sus propios elementos de trabajo. Destinado a atender proyectos económicos en las áreas de producción, comercio y servicio, pudiendo ser solicitados individualmente (necesitando garantía de un fiador) 0 a través de grupos solidarios ( 2 a 5 personas), con una tasa de interés al $12 \%$ anual. Los montos van desde Bs. 931.200 hasta Bs. 13.580 .000 , con un plazo de hasta 18 meses para los créditos hasta Bs. 4.850 .000 Bs. y 24 meses para los créditos entre Bs. 4.869 .400 y Bs. 13.580.000. Al igual que en el programa anterior, se cobrara el $5 \%$ de la tasa flat y $4 \%$ de los recrédito y las cuotas de pago agrupan capital más interés, pudiendo otorgar créditos con tiempo muerto de hasta 90 días contados a partir de la fecha de liquidación del crédito.

Créditos para cooperativas: Pueden ser solicitados por cooperativas que estén o no en funcionamiento, conformadas entre 5 y 20 personas (las cooperativas con más miembros se les canaliza la solicitud del crédito a través de otro organismo), a una tasa de interés al $12 \%$ anual. Los montos a otorgar van desde Bs. 931.200 hasta Bs. 25.066 .600 , con un plazo hasta de 18 meses para los créditos hasta un monto de Bs. 4.850 .000 y 24 meses para los que oscilan entre Bs. 4.869.400 hasta Bs. 25.006.600. Es necesario acotar, que para el año 2000 , el BPS solo contaba con dos productos financieros, como lo fueron los créditos a grupos solidarios y los créditos individuales; lo que deja ver la firme intención de la política de impulsar el sector cooperativo, incluyendo programas de créditos para el mismo.

\subsubsection{FONDEMI. Órgano rector de las microfinanzas}

FONDEMI nace de la autorización concedida al Presidente de la República para dictar medidas en el ámbito financiero, con el objeto de crear una banca de segundo piso, que conceda créditos de menor cuantía y lograr fortalecer las actividades microempresariales sustentadas en la iniciativa popular (FONDEMI, 2002: 5, 6).

FONDEMI se crea como ente rector del sistema micriofinanciero público; se origina en el año 2001, con el artículo 8 de la Ley de Microfinanzas; fue constituido como ente con personalidad jurídica y patrimonio propio e independiente de la hacienda pública nacional, teniendo como objetivo, apoyar las políticas de fomento, desarrollo y fortalecimiento del sistema microfinanciero (Presidencia de la República Bolivariana de Venezuela, 2001a: 11).

La misión formalmente establecida a FONDEMI es contribuir a la superación de la pobreza a través de la asistencia técnica y del otorgamiento de créditos, incrementando la tasa de ocupación, ofreciendo servicios basados en la promoción y desarrollo del Sistema Microfinanciero. Su visión está orientada a ser el ente rector del sistema microfinanciero, con la responsabilidad de conducir su desarrollo y fortalecimiento, basándose en principios de justicia social, capaz de mejorar las condiciones socioeconómicas y la calidad de vida del sector menos favorecido de la población para que éstos sean partícipes del desarrollo económico y social del país (FONDEMI, 2002: 15, 16).

FONDEMI opera como institución de segundo piso, ofreciendo servicios fi- 
nancieros y no financieros, a través de los entes de ejecución; constituidos según los requisitos exigidos en la Ley de Microfinanzas; conformándose así como una institución concentradora de los recursos del sector microfinancierio. Los servicios financieros son créditos a microproyectos presentados por la comunidad, y/o créditos a macroproyectos presentados por las cooperativas; $y$ los no financieros, son programas, proyectos, instrumentos y acciones para el adiestramiento, capacitación, formación, asistencia tecnológica, productiva y otros; llevados a cabo mediante cursos y talleres en las distintas áreas inherentes a la actividad productiva en pequeña y mediana escala (FONDEMI, s/f; FONDEMI y MEDES, s/f).

Los créditos son de dos tipos: individuales y mancomunados o solidarios. Se otorgan en forma gradual y escalonada, dependiendo de la capacidad, responsabilidad de pago y desarrollo del negocio; en todo caso para solicitar un crédito deben consignarse una serie de requisitos y pasos; los plazos para los créditos otorgados van desde el corto (hasta 2 años) hasta el mediano (de 2 a 5 años) plazo, aplicando un período muerto no mayor de 3 meses, con un interés a un 7\% (FONDEMI, 2003).

\subsubsection{BANMUJER. Una banca de género}

BANMUJER surge por decreto presidencial № 1243, registrándose formalmente, del cambio de denominación de Latino, Sociedad de Arrendamiento Financiero C. A, propiedad de la República Bolivariana de Venezuela, a Banco de Desarrollo de la Mujer C. A, Banca Comercial, a través de la Resolución № 327 el 21 de Agosto de 2001, por autorización de la Superintendencia de Bancos y otras instituciones financieras (FONDEMI, 2002: 119; BANMUJER 2002). Se crea dirigida a una población muy específica, como lo son las mujeres, propuesta presentada al Presidente de la República por el Instituto Nacional de la Mujer (INAMUJER), para desarrollar políticas públicas con visión de género, convirtiéndose en el primer banco estatal para la mujer (BANMUJER, 2003).

En la misión de BANMUJER se presenta como una institución financiera que facilita el acceso a los servicios financieros y no financieros en forma rápida y oportuna a las mujeres en condiciones de pobreza, asociadas para el trabajo; autogestionarias, que pertenezcan a empresas familiares, autoempleadas o desempleadas, con iniciativas para desarrollar una actividades económicas con el fin de integrarlas plenamente, en las dinámicas económicas y sociales del país. La visión plantea ser una institución para la construcción y potenciación de una economía al servicio equitativo de los hombres y mujeres del país, base para una sociedad justa y amante de la paz; en donde la economía está al servicio de las personas, como sujetos sociales activos o activas en la transformación productiva y como constructoras de sus propios destinos (FONDEMI, 2002: 121).

Los servicios financieros se constituyen en microcréditos para apoyar iniciativas productivas y cualquier proyecto de economía popular presentado por mujeres en condiciones de pobreza que no tienen acceso a los bancos tradicionales; y los no financieros están representados en la organización productiva de mujeres; la capacitación, formación y asistencia 
técnica para la elaboración de proyectos económicamente viables; entrenamiento en administración y manejo de microempresas; respaldo para desarrollar habilidades organizativas, de administración y liderazgo comunitario (BANMUJER, s/f).

BANMUJER otorga prioridad a los créditos para las mujeres organizadas en: 1) Unidades Económicas Asociativas (UEA), grupo conformado entre 2 y 9 personas, preferiblemente de 5 personas; constituidas por una coordinadora general, una administradora y tres responsables en las áreas de mercadeo, salud, y educación para la vida (BANMUJER, 2001; BANMUJER, 2004a); 2) Cooperativas, dando privilegio a las microcoperativas, constituidas por nueve personas como máximo (BANMUJER, s/f; BANMUJER, 2004a).

Hasta el año 2004, el préstamo inicial por persona era de Bs. 1.000.0000, pudiendo acceder a otro préstamo (al pagar puntualmente) con un incremento del $50 \%$, hasta alcanzar de manera progresiva un tope de cinco millones de bolívares; con un interés del $5 \%$ anual, $6 \%$ para los préstamos destinados al desarrollo agrícola ${ }^{8}$ y ningún interés para comunidades específicas; con un plazo de financiamiento entre 18 y 24 meses, con un máximo de 5 años y período de gracia mínimo de 2 meses (BANMUJER, s/f; BANMUJER, 2004a). Pueden otorgarse montos de 2 millones de bolívares, bajo consideración de la junta directiva; para las cooperativas el monto del crédito será de 10 millones de bolívares, independientemente del número de integrantes (BANMUJER, 2004a).

En BANMUJER no tienen sucursales, ya que cuenta con una red de promotoras que visitan las comunidades y contactan personalmente a las mujeres y organizaciones ya existentes, para ofrecerles sus servicios, focalizando el trabajo en los 149 municipios más pobres del país (BANMUJER, $\mathrm{s} / \mathrm{f}$ ).

Si bien es cierto, que la política de economía social de BANMUJER se encuentra dirigida hacia los sectores más vulnerables, focalizando en la población de mujeres en condiciones de pobreza y pobreza extrema; no menos ciertos es, que en está política no se maneja la misma concepción de las políticas neoliberales aplicadas para compensar efectos de ajuste económico. Es decir, la focalización es vista en el nuevo período gubernamental como una acción dirigida hacia la búsqueda de una mayor justicia y equidad social, tendiente a mejorar las condiciones de empleo productivo y el ingreso familiar, centrado en los núcleos de desarrollo endógeno, considerando las particularidades de cada región y enfatizando en la constitución de organizaciones cooperativas, más allá del empresario individual, promovido por las políticas neoliberales.

Reconociendo la dimensión tanto social como económica, de la economía social y apoyándonos en lo expuesto por Ochoa (2003), quien define las políticas sociales como presentes en todas las pofue el programa Siembra y produce lo que necesita el país (BANMUJER y MEDES, 2003b). 
líticas (en menor o mayor medida) y diseñadas también para la economía; podemos afirmar que la política de economía social que promueve el Estado en el capitalismo, se plantea entre sus objetivos la amortiguación de las desigualdades propias de las relaciones de producción capitalista, tal como lo expresa Olesker (2001); quien afirma que para combatir las desigualdades se deben implementar políticas dirigidas a la amortiguación de las desigualdades sistémicas (nivel básico de desigualdades), entre las cuales se encuentran las políticas de empleo y políticas de reducción del impacto de la exclusión (nivel agravado de exclusión), focalizando los sectores más excluidos.

Es decir, es necesario aplicar políticas para reducir el impacto de la exclusión agravada, originadas con las desigualdades del capitalismo; dentro de estas políticas no solo se encuentran las dirigidas hacia el empleo, sino que deben alcanzar a los sectores más excluidos; actualmente, este tipo de política se diferencia del período neoliberal, ya que la orientación y el enfoque del mismo, fue sólo para compensar efectos del ajuste económico y con carácter transitorio. En este sentido, dando prioridad a los sectores excluidos, el gobierno nacional formuló la "Agenda Bolivariana para el Desarrollo Endógeno", en donde se estimula la desconcentración territorial, el desarrollo de la economía social y se ejecutan diferentes programas (Fundos Zamoranos, las Zonas Especiales, Plan de Alfabetización Misión Robinson, Misión Guaicaipuro, Plan Especial de Seguridad Alimentaria) a los que BANMUJER otorga especial atención (BANMUJER, 2003b).
Dentro de la perspectiva del desarrollo endógeno, se lleva a cabo desde Octubre del año 2003, en convenio con el Programa de Desarrollo de las Naciones Unidas (PNUD), el proyecto "Desarrollo Humano Local, Gobernabilidad y Equidad de Género". En dicho proyecto se les otorga a las usuarias (organizadas en UEA o en cooperativas), las herramientas necesarias de planificación local, con el desarrollo de actividades productivas para insertarse en los núcleos de desarrollo endógeno desde sus respectivas localidades, a través de las cadenas productivas (microcadenas productivas), propiciando una competitividad solidaria y complementaria (BANMUJER 2004b).

\subsection{EI BANDES}

EI BANDES nace producto de la transformación del Fondo de Inversiones de Venezuela, mediante el decreto con rango y fuerza de Ley № 1.274 , en el año 2001. En Septiembre de 2003 pasa a ser coordinado por el MEDES; es un instituto autónomo que tiene como objeto realizar operaciones financieras y técnicas en el ámbito nacional e internacional a corto, mediano y largo plazo, con la administración de recursos y fomento de acciones conducentes a expandir, diversificar y desconcentrar la infraestructura social y productiva para el desarrollo integral del país (Presidencia de la República Bolivariana de Venezuela, 2001d).

Su Misión es promover el desarrollo económico, social y sustentable del país, mediante el apoyo técnico y financiero. En la Visión se plantea ser el banco líder para el desarrollo sustentable del país (Banco de Desarrollo Económico y 
Social, s/fb). La orientación del gobierno hacia un modelo de desarrollo enfocado en lo sustentable, quedó expresa en las organizaciones que surgieron en el contexto en el cual se originaron dichos planteamientos. Es posteriormente cuando surgen las tesis del desarrollo endógeno.

Para llevar a cabo las actividades del BANDES, relacionadas con la economía social, se creó la Vicepresidencia de Promoción y Desarrollo de la Economía Social (VPDES), a finales del año 2002; como área con el propósito de incorporar al desarrollo sostenido y sustentable a los sectores sociales marginados del sector económico a través del sector microfinanciero y cooperativo (BANDES, 2004a).

EI BANDES se orienta no solo al fomento de este sector de la economía social, sino a la asistencia de grandes proyectos industriales. Es decir, por ser banco de desarrollo no sólo tiene entre sus funciones el sector microfinaciero y de las cooperativas, cumple además, otras funciones más allá del ámbito específico de la economía social; de esta forma ha apo- yado al Estado venezolano en la ejecución de la Agenda Bolivariana para la Coyuntura y Desarrollo Endógeno, Plan de Inversiones Públicas, desarrollando una serie de programas en distintas áreas ${ }^{9}$ para dar cumplimiento a sus funciones (BANDES, 2003:12); áreas en las cuales no nos detenemos.

Entre los programas de financiamiento ejecutados por el BANDES, se destacan los siguientes: el programa de financiamiento concesional a microempresas, el programa de financiamiento concesional a cooperativas, el programa de desarrollo de la micro-industria "Monta tu Negocio" (Plan Endógeno), programa alimentario ${ }^{10} \mathrm{y}$ el programa proyecto a zonas especiales de desarrollo sustentable (ZEDES), entre otros (BANDES, 2004b: 5).

El programa de financiamiento para cooperativas ${ }^{11}$ se planteó como objetivo, fortalecer la economía social participativa y protagónica a través del financiamiento de las actividades productivas y de la asistencia técnica a organizaciones cooperativas, a fin de contribuir a la

9 Asimismo, ha desarrollado otros programas de carácter social, entre los cuales se encuentra el apoyo a las áreas de salud (dotación y optimización de hospitales públicos, la construcción y ampliación de clínicas populares, equipamiento y financiamiento de la red primaria); educación (rehabilitación y mantenimiento de las escuelas bolivarianas); reactivación productiva (fábricas de fábricas y la producción de equipamientos de los Mercados Populares (MERCAL); rehabilitación de infraestructura (Plan Reviva y Avispa); proyectos de crecimiento regional (Fondo Nacional para el Financiamiento de las Zonas Especiales de Desarrollo Sustentable (FONZEDES) (BANDES, 2003: 2).

10 Apoyando el Programa de Seguridad Agroalimentaria (PESA), a través del cual se creó MERCAL.

11 Los sectores financiables son: agroalimentario, industria y servicios conexos a la industria, industria e hidrocarburos, turismo, infraestructura, servicios, entre otros (MEDES y SUNACOOP, $\mathrm{s} / \mathrm{f})$. Las condiciones generales del financiamiento enmarcan un plazo de 1 a 10 años; interés del $12 \%$ anual; período de gracia, dependiendo de la actividad; garantías, con fianzas solidarias y otras acordes a la naturaleza de cada sector (MEDES y SUNACOOP, s/f). 
democratización de capital. El BANDES financia programas globales de créditos a cooperativas, pero, sus recursos financieros son canalizados a través de las instituciones del sistema microfinanciero (BANMUJER, BPS, FONDEMI) y otras instituciones (Banco Industrial de Venezuela; Instituto Nacional de la Pequeña y Mediana Industria; Fondo de Desarrollo Agropecuario, Forestal y afines; Banco de Fomento Regional Los Andes; y Fondo de Crédito Industrial), que administran los créditos que ayudan a las cooperativas para emprender sus negocios; en este sentido, también ha funcionado como una institución de segundo piso (MEDES y SUNACOOP, s/f).

\subsection{EI MINEP}

EI MINEP sustituye el MEDES en una segunda etapa o fase de avance de la política de economía social, en la que se destaca la concepción del desarrollo endógeno; entendido en esta etapa como desarrollo por dentro y desde adentro, con la constitución del modelo económico mediante una red de unidades productivas con diversos grados de magnitud, composición y tecnologías: empresas familiares, microempresas, unidades cooperativas (Lanz, 2004a:3). Este autor afirma que es necesario superar el sesgo economicista o tecnocrático, o visiones simplista, referente a lo endógeno, redu- ciéndolo a las internalidades técnico productivas, sin considerarlo de manera integral desde el punto de vista político-cultural y es por ello que se debe incluir las diversas derivaciones de la economía social que están fundadas en valores cooperativos y solidarios. La creación del MINEP es anunciada en Septiembre del año 2004, por el presidente de la República, en el programa Aló Presidente, número 203. De está manera las organizaciones adscritas al MEDES pasan a ser coordinadas por el MINEP, incorporando además otras instituciones existentes ${ }^{12}$.

EI MINEP tiene como misión la coordinación y planificación de las políticas para fomentar el surgimiento de emprendedores y construir microempresas, cooperativas y unidades de producción autosustentables que aporten bienestar a la colectividad en general; dignificar el trabajo productivo y la calidad de vida de las familias; fortalecer la política microfinanciera, al orientar la entrega de microcréditos de forma coordinada y focalizando el esfuerzo en torno a los núcleos de desarrollo endógeno. Su visión, en conjunto con todas la instituciones, consiste en integrar los objetivos para ocupar equilibradamente todo el territorio nacional con población, infraestructura, servicios y actividades productivas, es decir, impulsa la descentralización desconcentrada (MINEP, 2005).

Actualmente el MINEP, es el ente coordinador de la misión Vuelvan. Caras,

12 Se adscriben a la nueva institución: El instituto de Desarrollo Rural (INDER-CIARA), Instituto Nacional de Cooperación Educativa (INCE), la Superintendencia Nacional de Cooperativas (SUNACOOP), y el Fondo de Desarrollo Agropecuario, Pesquero, Forestal y Afines (FONDAFA). 
que se origina en el año 2004, dirigida por la Ministra del Trabajo, con el propósito fundamental de promover el cambio del modelo económico, social, político, cultural, centrándose en la educación y el trabajo (Lanz, 2004: 1); es decir, Vuelvan Caras busca la modificación de la estructura de dominación económico y social y la construcción del modelo de desarrollo endógeno. En este sentido, se ponen en marcha los núcleos de desarrollo endógenos, teniendo como pilar fundamental la economía social, con la participación de empresas de carácter social, como cooperativas y las asociaciones de productores (Vuelvan Caras, 2004).

Según Carlos Lanz (2004a), la Misión Vuelvan Caras, tienen sus antecedentes en el programa "Todas las Manos a la Siembra", el cual se planteó "un anclaje en el lugar, en la parroquia, en la localidad, en el caserío; que tiene sus raíces sembradas en la conciencia, en la organización popular". El proyecto "Todas las Manos a la Siembra", se originó en una coyuntura de desabastecimiento en las regiones, de la dieta básica de la población y estudiando la situación agroalimentaria del país se plantearon políticas estadales que se concentrasen sobre la producción, procesamiento, distribución y comercialización de los productos básicos de la dieta alimenticia (Gabinete en Crisis, 2003: 1). En dicho proyecto se hace referencia al desarrollo local sustentable en lugar de utilizar la concepción o terminología de desarrollo endógeno.

Para la misión Vuelvan Caras, el desarrollo endógeno es una forma de llevar adelante la transformación social, cultural y económica de la sociedad, basada en la reconquista de las tradiciones, el respeto al medio ambiente y las relaciones equitativas de producción, otorgando poder a las comunidades organizadas para que desarrollen las potencialidades agrícolas, industriales y turísticas de sus regiones; es incorporar a los excluidos del sistema educativo, económico y social; es construir redes productivas donde todos participen en igualdad de condiciones y accedan fácilmente a la tecnología y el conocimiento; es poner al servicio de la gente toda la infraestructura del Estado que habían sido abandonadas (campos industriales, maquinarias, tierras ociosas, entre otros) para generar bienes y servicios, en definitiva, transformarnos nosotros mismos para transformar la sociedad (Misión Vuelvan Caras, 2004).

El sector de la economía social, como cuestionador del modo de producción capitalista en el actual gobierno afianza su esencia misma al ser orientado hacia el cambio de la estructura económica dominante, basándose en una economía autogestionaria y cooperativa. Según Lanz (2004ㄹ: 4), el desarrollo endógeno se anota en un esfuerzo por el cambio de las estructuras que originan las injusticias y desigualdades; por lo que en el actual gobierno, por mandato constitucional se viene impulsando la economía popular como una opción alternativa frente al modelo neoliberal, que se basa en la explotación del trabajo y la obtención de la máxima ganancia, con sello de egoísmo posesivo.

\section{Conclusiones}

La política de economía social que se propone impulsar el gobierno actual bajo el mandato de Chávez, se inserta 
dentro de una nueva concepción del desarrollo, que en principio se orientó hacia lo sustentable, para posteriormente enfocar el componente endógeno.

La primera etapa de la política alternativa de economía social, afianzó diversos cambios materializados en el nuevo marco constitucional que la soporta, en la creación de la Ley de Microfinanzas, la actual Ley de Cooperativas y en diversas instituciones para llevar a cabo los diferentes programas que promueven la economía social en Venezuela. Asimismo, evitando la dispersión de esfuerzos en las organizaciones creadas, se planteó la creación de una instancia de coordinación, llevada a cabo con el nombramiento del MEDES, teniendo como objetivo ser el Ministerio promotor de la economía social en Venezuela; por lo cual posteriormente se constituye el MINEP.

El nuevo gobierno da prioridad a la integración de lo económico y lo social, al igual que promueve y protege estrategias productivas solidarias, bajo formas de organización como las microempresas y las cooperativas.

De igual manera las diferentes instituciones han llevado a cabo una serie de programas entre los que se encuentran algunos de vieja data, de tipo compensatorios y focalizados, beneficiando a una población de niños, adoslecentes y ancianos, ya no con el interés de compensar medidas de ajuste estructural y bajo un lineamientos neoliberales o cortopalcistas y trasnsitorios; sino como lo expresa Olesker (2001), sino para aplicar políticas que eviten la exclusión agravada, dirigidas a atacar los efectos de las desigualdades sistémicas causadas por el modo de producción capitalista, como parte de su lógica de funcionamiento que se expresa en asimetrías en todo el entramado social.

Otros de los programas ofrecidos se orientan hacia el sector de las microfinanzas y cooperativo; destacando el apoyo dado a programas que fortalecen a este último sector que como lo afirman López y Ochoa (2002) se constituyen en un proceso de producción alternativo a la gran empresa capitalista y pequeña empresa flexible.

En una segunda etapa, privan algunos cambios como la creación del MINEP, para coordinar las diferentes instituciones del Estado que llevasen a cabo la política de Economía Popular, por lo que se suman a este organismo otras instituciones además de las ya antiguamente dirigidas por el MINEP.

Finalmente se da impulso a un nuevo programa como lo es Vuelvan Caras, enfocado en el desarrollo endógeno que aún se encuentra en una etapa de definición y construcción, en búsqueda de cambiar la estructura dominante económica y social, fundamentalmente basada en nuevas formas socioproductiva y culturales, con la puesta en marcha de nuevos ejes de desarrollo y formas colectivas de organización en las que se centra la economía social.

\section{Referencias Bibliográficas}

Asamblea Nacional Constituyente (ANC) (1999), Constitución de la República Bolivariana de Venezuela. Gaceta Oficial Extraordinaria № 5.453 Caracas.

Banco del Pueblo Soberano (s/f), El Banco que le da Poder a los Pobres. Caracas. 
Banco del Pueblo Soberano (1999), Estatutos Sociales del Banco del Pueblo Soberano C. A. En El Informe Empresarial. Año IX. № 4498. Editorial Novia Grafía C. A. Caracas.

Banco del Pueblo Soberano (2003), Informe de Gestión 2003. Caracas.

Banco de Desarrollo Económico y Social de Venezuela (s/fa), Ministerio para el Desarrollo de la Economía Social. Banco de Desarrollo Económico y Social de Venezuela. Caracas.

Banco de Desarrollo Económico y Social (s/fb), "BANDES. Nuestra Mejor Oportunidad". Caracas.

BANDES (2003), BANDES en Líneas. Boletín Institucional. Año 1. № 4. Diciembre. Caracas.

BANDES (2004a), Manual de Organización. Caracas.

BANDES (2004b), BANDES en Línea. Boletín Institucional. Año 2. № 5. Caracas.

BANMUJER (2001), BANMUJER. Un Banco Diferente. Caracas.

BANMUJER. (2002), Estatutos del Banco de Desarrollo de la Mujer, C.A. (BANMUJER). Banca Comercial. En Repertorio Forense. Año XXXIV. № 12.704-2. Caracas.

BANMUJER (2003a), BANMUJER. En www.banmujer.gov.ve. Consulta realizada el 25 de Septiembre.

BANMUJER; MEDES (2003b), Informe de Gestión Año 2003. Caracas.

BANMUJER (2004a), Revisión de las Políticas de Servicios Financieros y No Financieros a Impulsar en el año 2004. Caracas.

BANMUJER (2004b), Noticias BANMUJER. Boletín № 3. Caracas.

BANMUJER; MEDES (s/f), BANMUJER... el banco diferente. Caracas.

Barrantes, César (1997), El Apoyo a la Economía Popular en Venezuela en Venezuela. ¿Hacia una Política Social
Orgánica de Estado? Fondo Editorial Tropykos. FACES UCV. Caracas.

Esteller, David (1995), Democracia y Cooperativismo. UCV. Ediciones Biblioteca. Caracas.

FONDEMI (2002), Humanizando las Finanzas. Caracas.

FONDEMI (2003), FONDEMI. En www.fondemi.gov.ve. Consulta realizada el 25 de Septiembre.

FONDEMI y MEDES (s/f), Las Microfinanzas son la Revolución. Economía Social... Un Verdadero Modelo de Desarrollo y Justicia Social. Caracas.

FUS (s/fa), Programa DUE. Dotación de Uniformes Escolares. Imagen Escolar. Caracas.

FUS (s/fb), Programa Alimentación Escolar. PAE. Caracas.

Gabinete en Crisis (2003), Proyecto Todas las Manos a la Siembra. Caracas

IAFUS (s/f), Datos Gerenciales. Caracas. Venezuela.

Lanz, Carlos (2004a), La Propuesta del Desarrollo Endógeno tiene que partir de otros Valores, de otra Concepción de la Economía, de lo Social, de lo Político. En Revista Laberinto. En http://laberinto.uma.es/. Consulta realizada el 7 de febrero de 2005.

Lanz, Carlos (2004b), El Desarrollo Endógeno y la Misión Vuelvan Caras. Fundamentos Conceptuales de la misión Vuelvan Caracas. Documento. Caracas. En: http/www.aporrea.org/ dameletra.php?docid=7708. Consulta realizada el 6 de febrero de 2005.

López, Carlos Eduardo (2003), Microempresas, Cooperativas y ONG's. Apoyo a las Organizaciones de la Economía Social desde la Reforma del Estado hasta la Revolución Bolivariana de Venezuela. Colección XLV Aniversario FACES. Universidad del Zulia. Maracaibo. Venezuela. 
López Carrasco, Carlos y Ochoa Henríquez, Haydée (2002), La política del gobierno de Chávez para el fomento de la economía social. Ponencia presentada en el Congreso de $\mathrm{Cl}$ RIEC. San Cristóbal. Venezuela.

MEDES; SUNACOOP (s/f), Programa de Financiamiento para Cooperativas. Cooperativismo para la Democratización del Capital. Tríptico Informativo. Caracas.

MINEP (2005), En www.minep.gov.ve. Consulta realizada el 4 de Enero de 2005.

Ministerio de Planificación y Desarrollo (MPD) (2001), Líneas Generales del Plan Nacional de Desarrollo Económico y Social de la Nación 2001-2007. Caracas.

Ministerio de Salud y Desarrollo Social (MSDS) (2000), La Revolución Social en la V República. La política Social de Venezuela. Cumbre Mundial de Desarrollo Social. Ginebra. Suiza. Caracas.

Movimiento V República (MVR) (1998), La Propuesta de Hugo Chávez para Transformar a Venezuela. Caracas.

Naciones Unidas (1997), Seminario de Alta Gerencia para Gobernadores y Alcaldes. Maracaibo. Venezuela.

Ocho Henríquez, Haydée (2003), La Política Social en el Gobierno de Chávez. Los Obstáculos a una Reforma para la Profundización Democrática. En el XI Congreso Federación Internacional de Estudios sobre América Latina y el Caribe (FIEALC). 24 al 27 de Septiembre de 2003. Osaka (Japón)

Olesker, Daniel (2001), ¿Qué Son, Cómo se Instrumentan y a Quién se dirigen las Políticas Sociales?. En www.internet.com.uy/ceronet/política_sociales_daniel_olesker.html. Consulta realizada el 5 de mayo de 2003.

Pacheco Simanca, José Luis (2004), Sistema Capitalista Mundial y Polo de Poder
Latinoamericano. Centro de Estudios Territorio Emergente. Fondo Editorial Question. Caracas.

Presidencia de la República Bolivariana de Venezuela (1999), decreto № 301 con rango y fuerza de Ley de Creación del Servicio Autónomo Fondo Único Social (SAFUS). Gaceta Oficial № 36. 800. Caracas.

Presidencia de la República Bolivariana de Venezuela (2001a), Ley de Creación, Estimulo, Promoción y Desarrollo del Sistema Microfinanciero. Con Exposición de Motivos y su Reglamento. Gaceta Oficial № 37.164 y Gaceta Oficial № 37.223. Caracas.

Presidencia de la República Bolivariana de Venezuela (2001b), Ley Especial de Asociaciones Cooperativas. En Gaceta Oficial № 37.285. Caracas.

Presidencia de la República Bolivariana de Venezuela (2001c). Decreto № .532 con fuerza de Ley de Creación del Instituto Autónomo Fondo Único Social (IAFUS). Gaceta Oficial № 37.322. Caracas.

Presidencia de la República Bolivariana de Venezuela (2001d). Decreto № $\mathbf{1 . 2 7 4}$ con rango y fuerza de Ley de Transformación del Fondo de Inversiones de Venezuela en el Banco de Desarrollo Económico y Social de Venezuela. Gaceta Oficial № 37.194. Caracas.

Presidencia de la República Bolivariana de Venezuela (2002). Decreto № 2.084 mediante el cual se nombra al Ministro de Estado para el Desarrollo de la Economía Social (MEDES), y decreto № 2.086 en el cual se dispone como Órgano Asesor de la Presidencia de la República en la Economía Social. Gaceta Oficial № 37.562. Caracas.

Presidencia de la República Bolivariana de Venezuela (2003). Decreto № 588 me- 
diante el cual se adscribe el Banco de Desarrollo Económico y Social (BANDES) al Ministro de Estado para el Desarrollo de la Economía Social. Gaceta Oficial № 37.773. Caracas.

Sunkel Oswaldo (1995), El Desarrollo Desde

Dentro. Un Enfoque Neoestructuralista para América Latina. CEPAL Fondo de Cultura Económica. México.
Vuelvan Caras (2004),.Vuelvan Caras. En www.vuelvancaras.gov.ve. Consulta realizada el 7 de Marzo de 2005.

\section{Entrevista}

Martínez, Adriana (2004). Gerente de Planificación y Presupuesto del IAFUS. Caracas 12 de Abril. 